\title{
Neural systems engaged by planning: a PET study of the Tower of London task
}

\author{
S. C. BAKER, ${ }^{* 1,3,4}$ R. D. ROGERS, ${ }^{2}$ A. M. OWEN, ${ }^{2}$ C. D. FRITH, ${ }^{1,5}$ R. J. DOLAN,${ }^{1,3,4}$ \\ R. S. J. FRACKOWIAK ${ }^{1,4}$ and T. W. ROBBINS ${ }^{2}$ \\ 'Wellcome Department of Cognitive Neurology, Institute of Neurology and MRC Cyclotron Unit, \\ Hammersmith Hospital, London, U.K.; \\ ${ }^{2}$ Department of Experimental Psychology, University of Cambridge, Cambridge, U.K.; \\ ${ }^{3}$ Royal Free Hospital School of Medicine, London, U.K.; \\ ${ }^{4}$ National Hospital for Neurology and Neurosurgery, London, U.K.; \\ and ${ }^{5}$ University College London, London, U.K.
}

(Received 6 February 1995; accepted 4 August 1995)

\begin{abstract}
The functional anatomy of planning was investigated using the Tower of London task. Activation was observed in a distributed network of cortical areas incorporating prefrontal, cingulate, premotor, parietal and occipital cortices. Activation in corresponding areas has been observed in visuospatial working memory tasks with the exception of the rostral prefrontal cortex. This area may be identified with the executive components of planning comprising response selection and evaluation. Enhanced neural activity in both this rostral prefrontal area and the visuospatial working memory system was associated with increased task difficulty. Copyright (C) 1996 Elsevier Science Ltd.
\end{abstract}

Key Words: planning; PET; Tower task; working memory; prefrontal cortex; parietal cortex.

\section{Introduction}

The essence of planning is the attainment of a goal through a series of intermediate steps which do not necessarily lead directly toward that goal. Extensive neuropsychological evidence has established the central role of the frontal lobes in this process $[24,50]$. The Tower of London task - in which the subject must rearrange, in the minimum number of moves, a set of three coloured balls arranged on pegs, so that the final configuration matches a specified goal state-has proved a useful test for the investigation of the role of prefrontal cortex in higher-order cognitive processes $[27,28,42]$. The key feature of the Tower of London task is that it is possible for the subject to plan the complete sequence of moves required to solve the problem in advance of making a response.

Easy Tower of London problems may be solved automatically by selection of the appropriate moves following inspection of the array and require minimal planning. In

* Address for correspondence: MRC Cyclotron Unit, Hammersmith Hospital, Ducane Road, London W12 0HS, U.K. more difficult problems the immediate attainment of one subgoal may conflict with the attainment of more appropriate subgoals that lead to the final goal position. In these difficult problems it is necessary to look ahead and select the appropriate sequence in which subgoals are reached. It is this requirement for anticipation and the representation of the consequences of one course of action on another that is the cardinal feature of planning [42].

The complex cognitive process involved in performance of this task can be broken down into component subprocesses. The initial and goal states must be processed with attention directed to the colour and spatial configuration of the balls, a subgoal must be defined, a sequence of moves directed toward its attainment selected and the intermediate problem stages generated and represented in working memory. Finally the consequences of each sequence of moves must be evaluated with respect to attainment of other subgoals and a new sequence selected if necessary.

The original study of Shallice [42] found that patients with left frontal lesions were significantly more impaired on this task than those with lesions on the right. However, using a computerised version of the task, Owen et al. [27], 
found no difference in the magnitude of the deficit with right- and left-sided lesions. Performance of the Tower of London task correlates highly with performance on other strategy tasks that involve information processing in spatial working memory $[27,28]$.

Considerable neuropsychological evidence indicates that prefrontal cortex is heterogenous with respect to function [47] and positron emission tomography (PET) has proved a powerful technique for investigating its functional organisation. Previous functional imaging studies of the Tower of London task have produced conflicting results. Andreasen et al. [1] using the Xenon133 technique, found activation in left mesial prefrontal cortex, parietal and occipital cortex, whereas Morris et al. [25], in a SPECT study using a 'region of interest' analysis, reported left dorsolateral prefrontal activation. In these studies, subjects moved coloured balls displayed on a touch-sensitive screen until they reached the goal state. In the study by Andreasen et al. the control condition comprised an undulating coloured display while in the study by Morris et al. subjects were cued to perform the same sequence of moves. The discrepancies between these studies may reflect the nature of the control tasks and the technical limitations of the techniques used.

In the present study we have used the 'slow bolus' $\mathrm{H}_{2}{ }^{15} \mathrm{O}$ infusion technique [44] to investigate regional cerebral blood flow (rCBF) changes in normal subjects performing the Tower of London task. We used a computerised version of the task which differed in several aspects from previous versions $[25,27]$. In the present version the subject has to solve each problem using only 'mental' transformations of the initial position, before executing a single response to indicate the minimum number of moves needed to solve the problem. In the control task the visual display and motor response were explicitly matched. This version requires the subject to plan the entire sequence of moves in their 'mind's eye'. In contrast to earlier versions [e.g. 39] the solution times of normal subjects showed a monotonic increase over problem difficulty and averaged about $25 \mathrm{sec}$. This version of the task has been shown to be sensitive to frontal lobe damage, patients with frontal lobe lesions make more attempts and take longer to reach the solution [28].

The study was designed to allow two comparisons: (i) comparison of activation in the Tower of London task with the control condition and (ii) comparison of activation in easy and hard task conditions. Subjects were presented with sequences of problems lasting 4-6 min. Concealed within these sequences were runs of easy problems ( 2 and 3 moves deep) and difficult problems ( 4 and 5 moves deep) which were presented during the acquisition phase of the scan.

\section{Methods}

\section{Subjects}

Six right-handed volunteers (five and one female) aged between 18 and 55 years took part in the study which was approved by the Hammersmith Hospital Ethics Committee and the Advisory Committee on the Administration of Radioactive Substances (ARSAC) UK. Informed consent was obtained from all subjects.

\section{PET scanning technique}

Regional cerebral blood flow was measured with a CTI model 953B PET scanner (CTI, Knoxville, TN, USA), with the interplane septa retracted [45], following a 'slow bolus' infusion of $\mathrm{H}_{2}{ }^{15} \mathrm{O}$ [44], integrated counts per pixel during the $90 \mathrm{sec}$ acquisition frame providing an index of $\mathrm{rCBF}$. An automatic pump flushed $11.2 \mathrm{mCi}$ of $\mathrm{H}_{2}{ }^{15} \mathrm{O}$ with normal saline through a cannula in an antecubital vein over $20 \mathrm{sec}$ at $10 \mathrm{ml} / \mathrm{min}$. Scanning commenced with detection of counts at the head, which began to rise after a constant delay and peaked between 30 and $40 \mathrm{sec}$ later in individual subjects. A total of 12 scans was performed repeated at $10 \mathrm{~min}$ intervals. A $30 \mathrm{sec}$ scan was acquired before each infusion for background activity correction. Correction for attenuation was made by performing a transmission scan with an exposed $68 \mathrm{Ge} / 68 \mathrm{Ga}$ external ring source before each session

\section{Cognitive activation paradigms}

Subjects were scanned in the presence of low background noise and dimmed ambient lighting. Stimuli were presented on a Taxan SV-775EV touch-sensitive computer screen controlled by an IBM PS/ 2 microcomputer. The screen was mounted at a viewing distance of approximately $50 \mathrm{~cm}$ so that the subject could easily touch the bottom part of the screen with the index finger of the dominant hand, which was rested on the chest between responses.

The Tower of London task. A typical display for this task is shown in Fig. 1. Two sets of three coloured balls were presented, one in the upper half of the screen and one in the lower half. Each set of balls was arranged in the manner of snooker or pool balls hanging in three pockets. One pocket could clearly hold all three balls, one could hold two balls, and one could be filled entirely by one ball. At the bottom of the screen, the numbers $1,2,3,4,5$ and 6 appeared in large $3 \mathrm{~cm}^{2}$ boxes comprising the response panel.

On each trial, the red, blue and green balls of both sets were shown in predetermined but different positions, the subject was asked to work out how they could be rearranged so that the balls in the lower part of the screen matched the position of the balls in the top half of the screen, in the minimum number of moves. Once the subject decided on the minimum number of moves required, he or she touched the appropriate box in the response panel, and the next problem was presented.

The rules governing the movements of the balls were explained to the subject and remained the same as for the original Tower of London [42], e.g. a ball could not be moved higher in a pocket unless there was another ball beneath it, a ball could not be moved to another pocket if another ball was on top of it. Subjects were told that only one response per problem was permitted and that they should not respond until quite sure of the correct answer. No feedback would be given during the scans.

The subject began working through one of the problem sequences (shown in Appendix 1) 90 sec before each of the Tower of London task scans was due to begin. At the start of the scan, the experimenter advanced forward to a run of exclusively easy problems (in the 'easy' task condition) or difficult problems (in the 'difficult' task condition) concealed within the sequence. After finishing this concealed run, the 


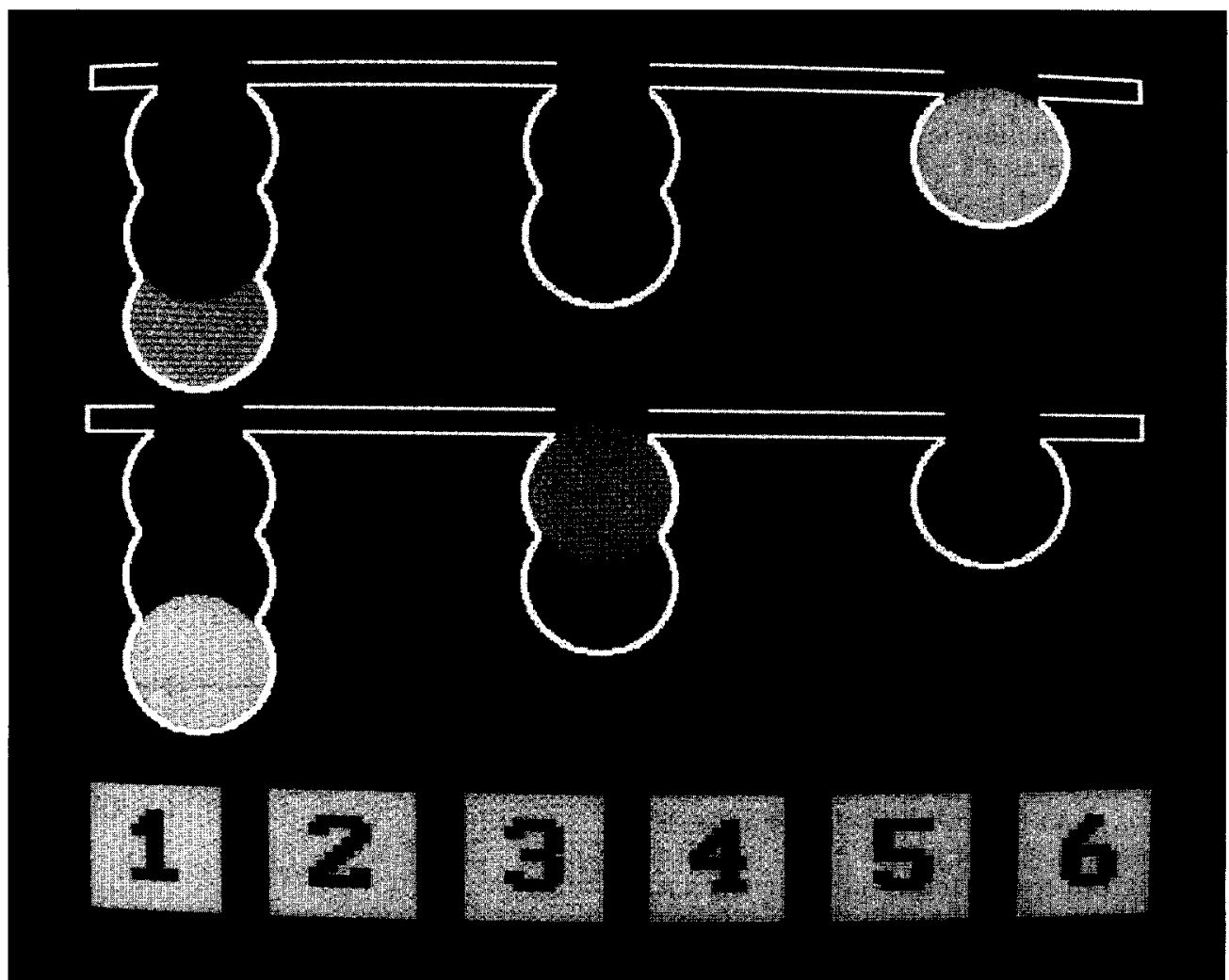

Fig. 1. Example of a Tower of London problem, illustrating the initial and goal positions in the upper and lower halves of the display respectively. The subject indicates the minimum number of moves required to solve the problem by touching the appropriate response panel at the bottom of the screen.

subject was returned to his or her original place in the sequence which was then completed. Preliminary tests had shown that each of the hidden runs occupy the typical subject for between $30-40 \mathrm{sec}$.

All the sequences of problems shown in Appendix 1 had the same distribution of $1,2,3,4,5$ and 6 moves, all problems were novel as selected from the problem-space for the Tower of London task.* Within the concealed runs, the easy problems always required 2 or 3 moves to solve, the difficult problems always 4 or 5 moves. The 1 and 6 moves problems were never scanned. None of the subjects detected the hidden runs.

The control task. In the control conditions of the experiment, the subject was required to monitor a sequence of displays at intervals corresponding to the latencies required to respond to the problems in the 'yoked' sequence of the task condition. Subjects had to detect a $1 \mathrm{sec}$ 'blink' of a randomly selected ball in the display and execute a constant motor response (touching the number ' 3 ' response in the centre of the response panel; see Fig. 1). The displays differed from the original displays in that the goal state and initial state were identical, avoiding unintended or 'automatic' planning.

Procedure. Each subject was scanned six times while solving Tower of London problems (three scans each with the easy and difficult conditions) and six times while performing the control task. Each subject first completed one scan with the easy condition and one scan for the difficult condition, followed immediately by their yoked control sequences (presented in the same order); this procedure was then repeated twice. Half the subjects began with the easy condition, half with the difficult.

Before scanning commenced, the subject was fully instructed

* Finch, G. (personal communication). The problem space for the Tower of London task. about the task and the control conditions and given one sequence with each as practice. Performance feedback was given at this stage, in order to ensure that the subjects understood the instructions.

\section{Data analysis}

Image analysis was performed on a SPARC 10 workstation (Sun Microsystems Inc., Surrey, UK) using interactive image display software (ANALYZE, Biodynamic Research Unit, Mayo Clinic [37]) and statistical parametric mapping (SPM Software, MRC Cyclotron Unit, London, UK). Calculations and image matrix manipulation were performed in PRO MATLAB (Mathworks Inc., New York).

Image reconstruction. Images were reconstructed into 31 slices by three dimensional back propagation using a Hanning filter, with a cut-off frequency of 0.5 cycles per pixel; the resulting images consisting of $128 \times 128$ pixels of $2.006 \times 2.006 \mathrm{~mm}$ having a resolution of $8.5 \times 8.5 \times 4.3 \mathrm{~mm}$ full width at half maximum.

Image analysis. The 31 original slices were interpolated to 43 planes in order to render the voxels approximately cubic. Images were automatically realigned to correct for head movement between scans [52] and transformed into a standard sterotactic space [13]. The stereotactically normalised images, consisting of 26 planes, correspond to the horizontal sections of the standard stereotactic atlas [48], each pixel represents $2 \times 2 \mathrm{~mm}$ with an interplanar distance of $4 \mathrm{~mm}$. Images were smoothed with a Gaussian filter 5 or 10 pixels wide in order to suppress high frequency noise in the images and accommodate normal variability in functional and gyral anatomy for group analysis. 
Statistical analysis. Differences in global activity within and between subjects were removed by analysis of covariance (ANCOVA) on a pixel basis with global counts as covariate and regional activity in each condition across subjects as treatment [12]. The ANCOVA generated a mean $\mathrm{rCBF}$ value, normalised to $50 \mathrm{ml} / 100 \mathrm{ml} / \mathrm{min}$, and associated error variance for every pixel in each condition. This adjusted rCBF represents a weighted mean over a sphere of approximately $20 \mathrm{~mm}$. Differences between the adjusted mean pixel values across conditions were assessed using the $t$ statistic [14], the resulting images of pixel $t$ values constituting a statistical parametric map [SPM( $t)]$. A further Gaussian filter of 4 or $8 \mathrm{~mm}$ full width at half maximum was applied at this stage.

In general, detection of extensive cortical activation in group studies is enhanced using wider smoothing filters whereas detection of more focal activations is improved using narrower filters. The optimal filter to detect an individual activation will depend on its spatial configuration and optimisation of detection of multiple activations requires a multifiltering strategy [34]. In this study the selection of primary and secondary filters was determined empirically, with a wide filter applied in the initial analysis of all data.

The omnibus significance of the SPMs was assessed by comparing the expected and observed distribution of the $t$ statistic under the null hypothesis of no treatment effect. The $\operatorname{SPM}(t) \mathrm{s}$ were additionally displayed as volume images of the highest $t$ values in three orthogonal projections and as surface renderings onto a standard cerebral cortex. In the comparison between levels of task difficulty the analysis was constrained to pixels of significant change in the initial comparison of the task and control conditions by orthogonal masking. SPM $(t)$ s were also transformed to the unit Gaussian distribution using a probability integral transform so that changes could be reported as $z$ scores.

\section{Results}

\section{Task performance}

The mean RTs and error proportions (arc-sine transformed) for those problems constituting the concealed 'easy' and 'difficult' runs were subjected to repeated-measure ANOVAs with difficulty $(2,3,4$ or 5 moves) as a single within-subject factor. Note that the latency means are based on incorrect as well as correct responses, because the activation data associated with these measures was collected as subjects worked through the sequences making only one response to each problem. Thus the RTs should be interpreted as the time taken to act on any solution and not necessarily the time to arrive at the correct one. Both performance measures are shown as a function of difficulty in Fig. 2.

Response times were significantly lengthened as the difficulty of the problems increased, $[F(3,15)=20.8$, $P<0.001]$. Newman-Keuls tests revealed that the mean times required to respond to the 4 and 5 move problems were both reliably longer than the mean times to respond to 2 and 3 move problems ( $P<0.01$ in all cases), and also that the subjects took significantly longer to respond to 5 move problems than to respond to 4 move problems $(P<0.01)$. The proportion of incorrect responses also reliably increased with problem difficulty, $[F(3,15)=5.2$,

\section{Reaction Times}



No. of Moves



No. of Moves

Fig. 2. Mean response times and proportion of problems solved in the minimum number of moves as a function of task difficulty. The response times represent the time to solution of both correct and incorrect responses.

$P=0.05]$. Further Newman-Keuls tests indicated that the subjects made more errors for the 5 move problems than for 2 and 3 move problems ( $P<0.05$ in each case).

To summarise, the performance of these six subjects clearly illustrates the usual marked increase in the difficulty associated with solving 4 and 5 move problems as compared to solving 2 and 3 move problems, and therefore replicates the typical pattern of results found with 
appropriate control samples in studies of planning in both frontal excision and Parkinson disease patients $[28,30]$.

\section{Task related changes in $\mathrm{rCBF}$}

The study was designed to allow analysis of the main effect of the task compared to the control condition and the effect of task difficulty using appropriately specified linear contrasts.

Increases of $\mathrm{rCBF}$ in the Tower of London task compared to the control condition. In the first comparison both levels of task difficulty and their respective control conditions were combined. Highly significant $(P<0.001)$ increases of $\mathrm{rCBF}$ in front and occipitoparietal cortical areas were associated with performance of the task (Fig. $3 a$; Table 1). In the frontal cortex the most significant activations were in premotor cortex bilaterally, highly significant activations were also present along the anterior cingulate gyrus (BA 32,24), extending to the supplementary motor area in the highest planes, and dorsolateral prefrontal cortex bilaterally (DLPFC; BA 9) though predominantly in the right hemisphere and the right rostrolateral prefrontal cortex (RLPFC; BA 10). At a lower threshold of significance $(P<0.01)$ an additional activation was revealed in the right anterior insula/frontal opercular area.

At a low threshold of significance $(P<0.05)$ contralateral $\mathrm{rCBF}$ increases are apparent in these frontal areas, immediately adjacent to extensive $\mathrm{rCBF}$ decreases. Selection of narrower filters in the analysis revealed the same pattern of right prefrontal activations, but in addition contralateral activations in the left anterior insula and rostrolateral prefrontal cortex were also highly significant $(P<0.001)$.

Extensive parietal activations $(P<0.001)$ were localised to the medial parietal cortex bilaterally (BA 7, precuneus), the left inferior parietal cortex (BA 40), bilateral superior parietal cortex $(P<0.01$, right hemisphere) and lateral occipital cortex (BA 18/19). Bilateral activations all reached higher significance in the left hemisphere (Table 1).

Subcortical activations were localised to the left cerebellar hemisphere and the vermis $(P<0.001)$ and extended from the anterior cingulate to the right thalamus $(P<0.01)$ and included the region of the right caudate nucleus. On selection of a narrower filter discrete activation foci could be distinguished in the anterior cingulate cortex and bilaterally in the thalamus $(P<0.01)$.

Decreases of $r C B F$ in the Tower of London task compared to the control condition. The principal decreases of $\mathrm{rCBF}$ in the task compared to the control condition $(P<0.001)$ were in the bilateral superior temporal cortex, extending on the right to the transverse temporal gyrus medially and to the hippocampus inferiorly, and on the left incorporating the middle temporal gyrus. In frontal cortex, rCBF decreases appeared in a swathe of anterior medial cortex extending from the precommissural anterior cingulate through the dorsomedial frontal cortex to the superior frontal gyrus. Further frontal $\mathrm{rCBF}$ decreases were present in bilateral superior frontal cortex (BA 8), left inferior frontal cortex, and at lower significance $(P<0.01)$, bilaterally in sensorimotor cortex (Fig. 3b; Table 2).

There were two foci of decreased $\mathrm{rCBF}$ in posterior medial cortex, at the rostral limit of the posterior cingulate gyrus (BA 31/24) and at its caudal border with medial parietal cortex (BA 23/31, precuneus).

\section{Effect of task difficulty}

Easy and hard conditions compared to their respective yoked controls. Comparison of the easy and hard task conditions with their respective yoked controls revealed
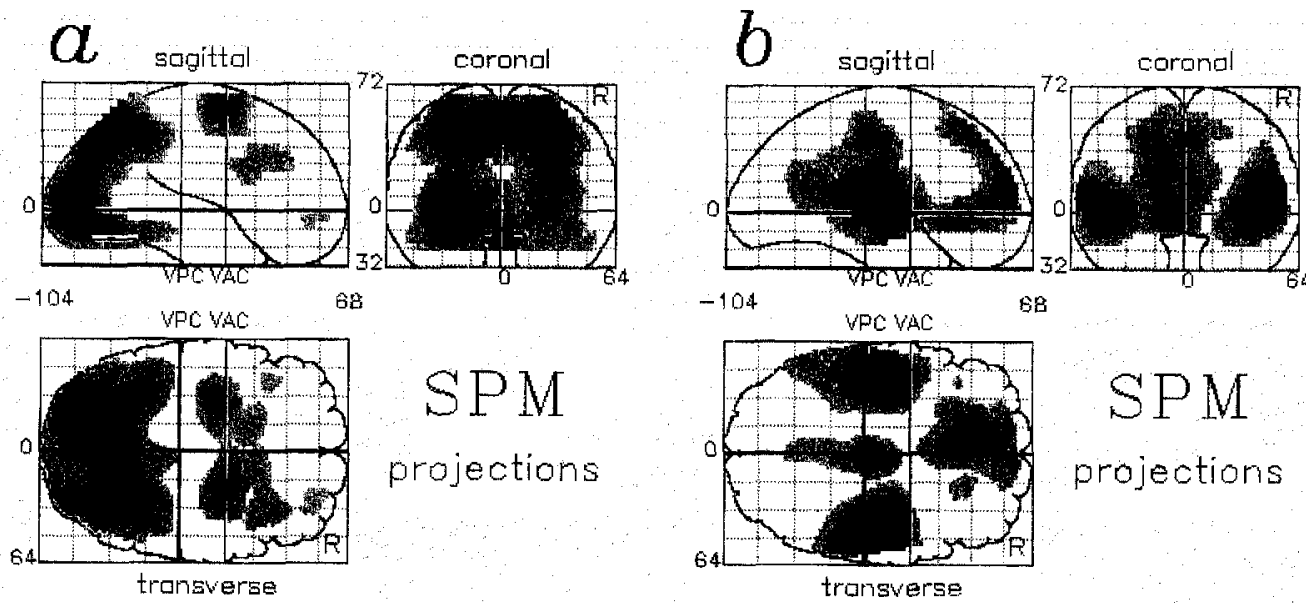

Fig. 3. Statistical parametric maps (SPMs) of the comparison of the Tower of London task condition with the control condition (a) increases and (b) decreases in regional cerebral blood flow (rCBF). Pixels exceeding a threshold level of significance of $P<0.01$ uncorrected for multiple comparison are displayed on sagittal, coronal and transverse projections of the brain, the left side of the brain is on the left side of the projections. The coordinates of the foci of maximal change of rCBF are given in Table 1. 
Table 1. Comparison of the Tower of London task with control conditions: Foci of significant $\mathrm{rCBF}$ increases

\begin{tabular}{|c|c|c|c|c|c|c|}
\hline \multirow{2}{*}{$\begin{array}{l}\text { Region of } \\
\text { activation }\end{array}$} & \multirow{2}{*}{$\begin{array}{l}\text { Left/ } \\
\text { right }\end{array}$} & \multirow{2}{*}{$\begin{array}{l}\text { Broadmann's } \\
\text { area }\end{array}$} & \multicolumn{3}{|c|}{ Talairach coordinates } & \multirow[b]{2}{*}{$Z$ score } \\
\hline & & & $x$ & $y$ & $z$ & \\
\hline $\begin{array}{l}\text { Rostrolateral } \\
\text { prefrontal cortex }\end{array}$ & $\mathrm{R}$ & 10 & 28 & 54 & -4 & 3.63 \\
\hline \multirow{2}{*}{$\begin{array}{l}\text { Dorsolateral } \\
\text { prefrontal cortex }\end{array}$} & $\mathrm{L}$ & 9 & -42 & 26 & 32 & 3.57 \\
\hline & $\mathrm{R}$ & 9 & 36 & 28 & 32 & 4.71 \\
\hline \multirow[t]{2}{*}{ Premotor cortex } & $\mathrm{L}$ & 6 & -30 & -4 & 60 & 7.79 \\
\hline & $\mathrm{R}$ & 6 & 22 & 0 & 60 & 7.62 \\
\hline \multirow{3}{*}{$\begin{array}{l}\text { Anterior cingulate } \\
\text { cortex }\end{array}$} & $\mathrm{R}$ & 32 & 4 & 12 & 44 & 3.29 \\
\hline & $\mathrm{R}$ & 32 & 12 & 20 & 28 & 3.66 \\
\hline & $\mathrm{L}$ & 24 & -16 & 14 & 24 & 4.38 \\
\hline $\begin{array}{l}\text { Anterior insula } \\
\text { cortex }\end{array}$ & $\mathrm{R}$ & 45 & 30 & 18 & 4 & 2.57 \\
\hline \multirow{2}{*}{$\begin{array}{l}\text { Superior parietal } \\
\text { cortex }\end{array}$} & $\mathrm{L}$ & $7 / 5$ & -28 & -46 & 60 & 3.98 \\
\hline & $\mathrm{R}$ & $40 / 5$ & 34 & -40 & 56 & 2.96 \\
\hline $\begin{array}{l}\text { Inferior parietal } \\
\text { cortex }\end{array}$ & $\mathrm{L}$ & 40 & -30 & -44 & 32 & 5.52 \\
\hline \multirow{2}{*}{$\begin{array}{l}\text { Medial parietal } \\
\text { cortex } \\
\text { (precuneus) }\end{array}$} & $\mathrm{L}$ & 7 & -14 & -66 & 44 & 11.1 \\
\hline & $\mathrm{R}$ & $19 / 7$ & 26 & -68 & 36 & 7.92 \\
\hline \multirow{3}{*}{$\begin{array}{l}\text { Lateral occipital } \\
\text { cortex }\end{array}$} & $\mathrm{R}$ & 19 & 28 & -80 & 16 & 7.71 \\
\hline & L & $18 / 19$ & -26 & -82 & 0 & 8.69 \\
\hline & $\mathrm{R}$ & $18 / 19$ & 28 & -84 & 0 & 6.48 \\
\hline Thalamus & $\mathrm{R}$ & & 2 & -6 & 8 & 2.87 \\
\hline $\begin{array}{l}\text { Cerebellar } \\
\text { hemisphere }\end{array}$ & $\mathrm{L}$ & & -16 & -66 & -12 & 7.91 \\
\hline Cerebellar vermis & & & 0 & -58 & -16 & 7.12 \\
\hline
\end{tabular}

The coordinates of the foci of maximal significant change of $\mathrm{rCBF}(P<0.01)$ in the standard stereotaxic space of Talairach and Tournoux [48] are given in $\mathrm{mm}$. $Z$ scores greater than 3.09 corresponding to $P<0.001$ are in bold type. Foci approaching significance with a $Z$ score between 2.33 and 3.09 are given in plain type.

Table 2. Comparison of the Tower of London task with control conditions: Foci of significant $\mathrm{rCBF}$ decreases

\begin{tabular}{|c|c|c|c|c|c|c|}
\hline \multirow{2}{*}{$\begin{array}{l}\text { Region of } \\
\text { activation }\end{array}$} & \multirow{2}{*}{$\begin{array}{l}\text { Left } \\
\text { right }\end{array}$} & \multirow{2}{*}{$\begin{array}{l}\text { Broadmann's } \\
\text { area }\end{array}$} & \multicolumn{3}{|c|}{ Talairach coordinates } & \multirow[b]{2}{*}{$Z$ score } \\
\hline & & & $x$ & $y$ & $z$ & \\
\hline \multirow{2}{*}{$\begin{array}{l}\text { Sensorimotor } \\
\text { cortex }\end{array}$} & $\mathbf{L}$ & 4 & -12 & -28 & 64 & 2.64 \\
\hline & $\mathrm{R}$ & 4 & 12 & -24 & 64 & 3.03 \\
\hline \multirow{3}{*}{$\begin{array}{l}\text { Superior frontal } \\
\text { cortex }\end{array}$} & $\mathbf{L}$ & 8 & -18 & 34 & 48 & 5.94 \\
\hline & $\mathrm{R}$ & 8 & 20 & 32 & 48 & 4.37 \\
\hline & $\mathbf{L}$ & 8 & -20 & 38 & 40 & 5.82 \\
\hline $\begin{array}{l}\text { Inferior frontal } \\
\text { cortex }\end{array}$ & $\mathrm{L}$ & 45 & -40 & 28 & 8 & 3.23 \\
\hline \multirow{4}{*}{$\begin{array}{l}\text { Dorsomedial } \\
\text { prefrontal cortex }\end{array}$} & $\mathrm{L}$ & 6 & -10 & 22 & 60 & 4.45 \\
\hline & $\mathrm{L}$ & 8 & -10 & 40 & 44 & 5.27 \\
\hline & $\mathbf{L}$ & 9 & -14 & 52 & 28 & 6.14 \\
\hline & $\mathbf{L}$ & 10 & 6 & 58 & 20 & 5.73 \\
\hline $\begin{array}{l}\text { Anterior cingulate } \\
\text { cortex }\end{array}$ & $\mathbf{L}$ & 24 & -8 & 26 & -4 & 6.79 \\
\hline \multirow{2}{*}{$\begin{array}{l}\text { Posterior } \\
\quad \text { cingulate cortex }\end{array}$} & $\mathrm{R}$ & $31 / 24$ & 2 & -16 & 40 & 6.88 \\
\hline & L & $23 / 31$ & -2 & -60 & 20 & 4.10 \\
\hline Superior temporal & $\mathrm{L}$ & 22 & -52 & -56 & 16 & 5.67 \\
\hline \multirow{2}{*}{ gyrus } & $\mathrm{L}$ & 22 & -42 & -14 & 4 & 8.66 \\
\hline & $\mathrm{R}$ & 41 & 46 & -26 & 12 & 9.87 \\
\hline $\begin{array}{l}\text { Middle temporal } \\
\text { gyrus }\end{array}$ & L & 21 & -52 & -28 & -8 & 4.72 \\
\hline
\end{tabular}

The coordinates of the foci of maximal significant change of $\mathrm{rCBF}(P<0.01)$ in the standard stereotaxic space of Talairach and Tournoux [48] are listed as in Table 1. 
common patterns of focal rCBF increases and decreases corresponding to the regional activations and deactivations in the combined task compared to control, differing only in the level of significance of rCBF changes attained in each region (Fig. 4a,b). The most striking difference between the two conditions was, however, apparent in the relative magnitude of the activations in the anterior insula/frontal operculum and rostrolateral prefrontal cortex. In the easy condition there was an extensive activation in the insula/operculum with a relatively circumscribed activation in the RLPFC. In contrast, in the difficult condition there was an extensive rostrolateral prefrontal activation with a relatively attenuated activation in the insular/opercular area.

Differences of $\mathrm{rCBF}$ in the hard compared to the easy Tower of London task conditions. Direct comparison of $\mathrm{rCBF}$ in the difficult and easy task conditions revealed relative increases in the difficult condition in the prefrontal, premotor and medial parietal cortices, comprising a subset of the activations in the combined comparison of task and control conditions (Fig. 4c). There was a single additional focal area of increased $\mathrm{rCBF}$ in the medial occipital cortex in this comparison that was not observed in the comparison of the hard task with its yoked control. In frontal cortex highly significant $(P<0.001)$ activations were restricted to the right DLPFC (BA 10/46) and bilateral premotor area (BA 6) and, at a lower threshold of significance $(P<0.01)$, the left DLPFC (BA 9) and right rostrolateral prefrontal cortex (BA 10).

Decreases of $\mathrm{rCBF}(P<0.01)$ attributable to task difficulty were restricted to the posterior cingulate gyrus (BA 31), hippocampi and insulae bilaterally and to the right sensorimotor cortex and the left cerebellar hemisphere.

\section{Discussion}

The important finding in our study is that a complex planning task produces focal activations in a distributed neocortical system encompassing both frontal and posterior parietal cortices. Opinions differ with regard to the localisation of function in the prefrontal cortex. One view derived from anatomical and physiological studies is that different areas of prefrontal cortex have an intrinsic sensory, mnemonic and motor executive capacity that is integral to that areas function. The alternative view is that different areas of prefrontal cortex have different and to some extent incommensurate functions, i.e. that functions are mapped across the prefrontal cortex. From consideration of previous functional imaging studies we can identify plausible neural substrates for some of the cognitive components of planning within the distributed system identified in this study: (a) a rostral prefrontal area engaged in sequence selection and evaluation; (b) a system for representation of intermediate problem states in visuospatial working memory, comprising DLPFC, posterior parietal and extrastriate visual cortices and (c) a system for their manipulation and the direction of attention comprising inferior frontal, premotor and anterior cingulate cortices. This system was revealed in the comparison of the Tower of London task with the control task and when difficult problems were compared to easy problems.

\section{Prefrontal cortex activation}

Three regions of prefrontal cortex were activated by the Tower of London task, dorsolateral and rostrolateral prefrontal cortex and an area at the junction of the anterior insula and inferior frontal gyrus. On the basis of previous PET studies and investigations in the nonhuman primate these focal activations can tentatively be associated with distinct cognitive subprocesses.

Dorsolateral prefrontal cortex and 'working memory'. Previous PET studies have demonstrated activation of dorsolateral prefrontal cortex associated with active representation of both spatial and non-spatial information $[3,16,21,33]$. Spatial working memory tasks predominantly activate right DLPFC while non-spatial tasks predominantly activate left DLPFC. It has been proposed that neural activity in the DLPFC has a specific role in holding information 'on-line' in 'working memory" [17]. Bilateral activation of DLPFC in the Tower of London task is consistent with its putative role in active maintenance of a representation of spatial and non-spatial features of the displays and has recently been reported in another PET study of a version of this task [28].

The working memory component of the Tower of London task allows evaluation of intermediate problem states with reference to the goal state. There is a strong correlation between performance on this task and a selfordered spatial working memory task [29]. However, the deficits on the spatial working memory task in frontal patients are almost entirely attributable to deficits in the strategy used to order responses rather than mnemonic function, indicating a close relationship between strategy generation and working memory systems.

Since previous studies allow us to attribute activation in DLPFC to the working memory component of the task, the highly significant activation in the rostrolateral prefrontal cortex may therefore be attributed to the executive processes concerned with the selection and evaluation of sequences of moves.

Rostrolateral frontal cortex and planning. There is a dearth of definitive lesion data concerning the functional role of the rostral prefrontal cortex, however activation of this region has been observed in a number of functional imaging studies employing a variety of cognitive paradigms. Activation of rostrolateral frontal cortex together with DLPFC was observed in 'random' movement and motor sequence learning paradigms $[8,20]$ and associated with encoding and retrieval from episodic memory $[18,43,49]$. Although these paradigms involve apparently 
diverse cognitive operations they have certain common features. Sequence learning and generation of random responses in man both require representation of previous responses in working memory and selection and evaluation of appropriate new responses, similarly the cognitive operations involved at encoding and retrieval from episodic memory involve organisation and evaluation of material in working memory. Co-activation of the rostral and dorsolateral cortices across such diverse tasks is consistent with a functional role in that component common to these tasks, namely the cognitive operations performed on material maintained in working memory.

The rostrolateral prefrontal cortex is interconnected with both the dorsolateral prefrontal and posterior parietal cortices and constitutes one component of an anatomically defined network for spatial cognition [41]. These connections provide an anatomical substrate for the functional interaction with spatial working memory. The anterior prefrontal lesions associated with impaired performance of the Tower of London task in group studies of patients with frontal lobe lesions $[27,42]$ would in most subjects have involved the rostral area activated in the present study. Bilateral activation in this region may allow relative sparing of planning ability following unilateral lesions.

\section{Visuospatial representation and working memory}

Parietal cortex: spatial representation and attention. Activation of medial (precuneus) and inferior parietal cortex has been associated with active representation of spatial location in delayed spatial response paradigms $[3,11,21]$, activation in inferior parietal cortex has been observed with imagined limb movement [46] and activation in superior parietal cortex with shifting visuospatial attention [6]. Precuneus activation has been found in a wide variety of experimental paradigms; alternating and moving checkerboard stimuli $[9,51]$, representation of shape and spatial location [3, 19], visual imagery [39] and cognitive tasks including retrieval from episodic memory $[18,33,43,49]$. The range of cognitive functions associated with activation of this region is consistent with a general role in the spatial organisation of mental representations.

Visual analysis and imagery. Analysis of the problems necessarily involves attention to the colours of the balls and their spatial configuration. Activation in extrastriate visual cortex corresponds to regions activated by attentional processing of both colour and shape $[6,23]$ and activation in these areas has been associated with visual imagery $[22,38,40]$ and commentaries, consistent with a role of imagery in the representation of intermediate problem states. Activation in the medial occipital cortex was only observed in the comparison of the hard and easy conditions, not in the comparison with the yoked control and may reffect differences in visual analysis, the easy problems being solved automatically following initial inspection.

\section{Role of motor systems in planning}

Premotor cortex. Activation of premotor cortex in the difficult task condition cannot be attributed to the response demands of the task as subjects made at most only two or three overt responses during the scan period. Premotor cortex activations were localised in the topographical representation of the upper limb [5]. Corresponding premotor areas have been activated in spatial delayed response tasks, even when subjects were not required to make overt responses during the scanning period [3,21] and have also been associated with imagined movement [46]. The frontal eye fields were not activated in this comparison which may reflect equivalent activation in the control task which also involved visual inspection. Manipulation of intermediate problem states in this task may be accompanied by imagined movement of the 'mind's eye and finger', reciprocal interconnections between premotor and posterior parietal cortex constituting the neurophysiological basis for image manipulation.

Anterior insula/frontal operculum. Activation in this region was predominantly associated with the easy problems and may reflect more automatic sequencing of 'moves' in this condition. Activation in the ventral frontal cortex has been observed in another PET study of a version of the Tower of London task [28] and in the control task involving remembered sequences of moves. Similar activation was found in the delay period of the delayed spatial response paradigm associated with representation or mental rehearsal of responses [3,21] and has also been observed in association with imagined movement [46].

Anterior cingulate cortex. The anterior cingulate gyrus has been consistently activated across a variety of tasks that require directed attention or selection of responses $[7,15,31]$ and in association with imagined movement [46]. In the present study, the caudal activation corresponds to the area activated in a delayed spatial response paradigm and other manual tasks, the more rostral activation foci correspond to areas activated in oculomotor tasks [3,32].

\section{Subcortical activations}

Interpretation of highly significant activations apparent in the cerebellar vermis and hemisphere is complicated by eye movement not being explicitly matched in the control conditions although limb motor responses were matched, these activations may reflect saccadic eye movement associated with active visual inspection of the initial and goal states though they are also consistent with a role in image manipulation. 
The activation in the region of the basal ganglia must also be interpreted with caution. The region of increased rCBF extended from the cingulate cortex to the thalamus; within this area focal activation was consistently observed in the thalamus, though the focus of maximal change of rCBF in the rostral area differed according to the degree of smoothing. Although we cannot identify the rostral structure with confidence, the present observations are consistent with activation of the caudate nucleus reported in the related version of this task [28].

\section{Neural correlates of task difficulty}

The principal difference between the hard and easy conditions was the reciprocal relation between the extent of activation in the insula/opercula area and rostrolateral prefrontal cortex (Fig. 4a,b). There was significantly greater activation in the rostrolateral prefrontal cortex (BA 10) in the hard condition compared to control than the easy condition compared to control. In contrast the easy condition was associated with more extensive activation in the ventral insula/opercula area. This was confirmed in the direct comparison of hard and easy conditions (Fig. 4c) in which increases in $\mathrm{rCBF}$ were present in two areas of prefrontal cortex, DLPFC and rostrolateral prefrontal cortex and also in premotor and medial parietal cortex.

An analogous reciprocal relationship between activation in prefrontal and insula cortex has been observed in a study of verb generation [35]. Initial performance was associated with activation of the DLPFC and decreased $\mathrm{rCBF}$ in the insula; with practice DLPFC was no longer activated, however activation could then be observed in the insula.

Easy problems, 2 or 3 moves deep, require image manipulation but involve minimal planning. The harder problems, 4 and 5 moves deep, require active representation of more intermediate states before achieving the goal state and this is reflected in the increased activation in those areas identified with the visuospatial
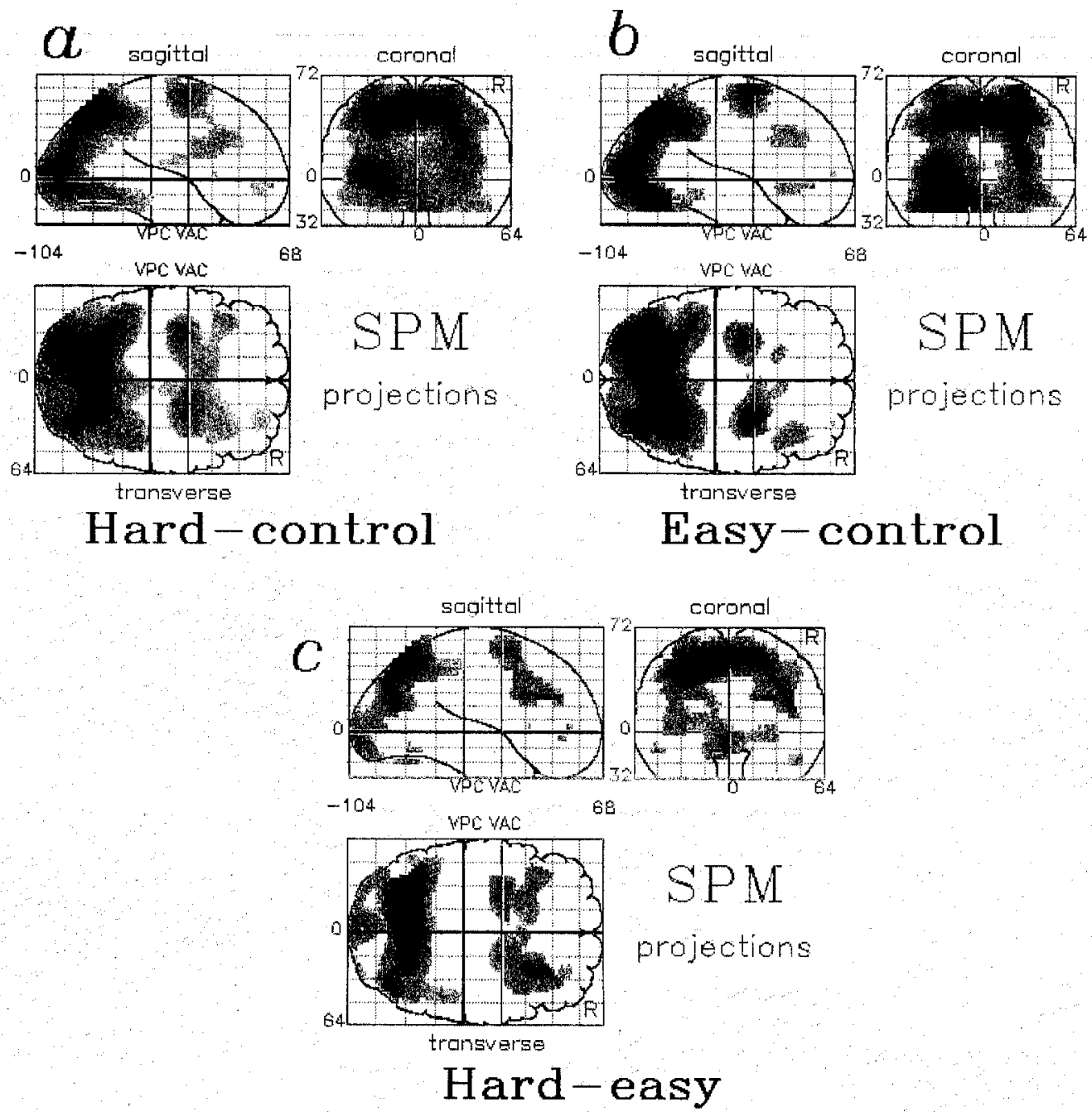

Fig. 4. SPMs of the increases of $\mathrm{rCBF}$ in the comparison of (a) the difficult Tower of London task condition with the control condition, (b) the easy Tower of London task condition with the control condition and (c) the difficult condition with the easy condition. Pixels exceeding an uncorrected threshold of significance of $P<0.01$ the Tower of London task compared to the control condition are illustrated as in Fig. 3. 
working memory component of planning. In addition the rostrolateral prefrontal cortex, identified with the executive processes in this task, revealed graded activation with increasing task difficulty.

\section{Conclusions}

The influential model of Norman and Shallice [26] proposed a general programming system, the supervisory attentional system (SAS), that was called into action when the demands of a task were non-routine. This model provided a firm theoretical perspective from which to regard complex problem solving by man and machine. The observation of a specific deficit in planning following anterior frontal lobe lesions provided the first plausible evidence for the separate anatomical location of such a general programming system in the frontal cortex [42].

The present study has benefited from the use of a high resolution scanner and the high sensitivity of the 3-D acquisition technique combined with statistical parametric mapping, which takes advantage of repeated measures in a group of subjects. By requiring subjects to represent all of the intermediate stages of a sequence of moves in working memory the present paradigm maximises that aspect of planning related to evaluation of the consequences of a course of action and provides direct evidence for the engagement of the rostral frontal cortex by the Tower of London task. The increased planning demands of the difficult problems were associated with enhanced activation in this region. Consistent with the putative role of this region as a 'general programming system' [42], it is engaged by a variety of linguistic and spatial tasks $[8,18,20]$.

Goldman-Rakic [17] has emphasised the central role of representational memory in complex behaviour and this is implicit in the original definition of working memory as "the temporary storage of information that is being processed in any of a range of cognitive tasks' [2]. In the Tower of London task it is possible to distinguish between the representation of material in working memory and the cognitive operation performed on the material represented. Previous functional imaging studies have delineated the distributed network of cortical areas involved in the 'temporary storage' of spatial and nonspatial information. This system is activated in its entirety in the present study. In the light of these studies we can plausibly attribute the specific cognitive processes associated with planning to the additional rostrolateral prefrontal area activated in the present study.

It remains for future studies to determine the precise nature of cognitive operations in which this system is engaged. Following Shallice [42] we propose that the critical element across tasks that will activate this rostral prefrontal area is the non-routine selection of cognitive strategies.
Acknowledgements-This work was carried out at the MRC Cyclotron Unit, Hammersmith Hospital. The Wellcome Trust support Dr Dolan, Prof Frackowiak and Prof Frith; Dr Robbins is supported through a programme grant from the Wellcome Trust. Dr Baker is a Wellcome Trust Mental Health Fellow. We are grateful to Prof Shallice for valuable discussion and the volunteers who took part in the study.

\section{References}

1. Andreasen, N. C., Rezai, K., Alliger, R., Swayze, V. W., Falum, M., Kirchner, P., Cohen, G. and O'Leary, D. S. Hypofrontality in neuroleptic-naive patients and in patients with chronic schizophrenia. Assessment with xenon 133 single-photon emission computed tomography and the Tower of London. Arch. Gen. Psychiatry 49, 943-958, 1992.

2. Baddeley, A. Working Memory. Oxford University Press, Oxford, 1986.

3. Baker, S. C., Frith, C. D., Frackowiak, R. S. J. and Dolan, R. J. The neural substrate of active memory for shape and spatial location in man. Eur. J. Neurosci. (Suppl. 7), 113.03, 1994.

4. Cavada, C. and Goldman Rakic, P. S. Posterior parietal cortex in rhesus monkey: II. Evidence for segregated corticocortical networks linking sensory and limbic areas with the frontal lobe. J. comp. Neurol. 287, 422-445, 1989.

5. Colebatch, J. G., Deiber, M. P., Passingham, R. E., Friston, K. J. and Frackowiak, R. S. Regional cerebral blood flow during voluntary arm and hand movements in human subjects. J. Neurophysiol. 65, 1392-1401, 1991.

6. Corbetta, M., Miezin, F. M., Dobmeyer, S., Shulman, G. L. and Petersen, S. E. Selective and divided attention during visual discriminations of shape, color, and speed: Functional anatomy by positron emission tomography. J. Neurosci. 11, 2383-2402, 1991.

7. Corbetta, M., Miezin, F. M., Shulman, G. L. and Petersen, S. E. A PET study of visuospatial attention. J. Neurosci. 13, 1202-1226, 1993.

8. Deiber, M. P., Passingham, R. E., Colebatch, J. G., Friston, K. J., Nixon, P. D. and Frackowiak, R. S. Cortical areas and the selection of movement: A study with positron emission tomography. Exp. Brain Res. 84, 393-402, 1991.

9. Fox, P. T., Fox, J. N., Raichle, M. E. and Burde, R. $M$. The role of cerebral cortex in the generation of voluntary saccades: A positron emission tomographic study. J. Neurophysiol. 54, 348-369, 1985.

10. Fox, P. T. and Raichle, M. E. Stimulus rate dependence of regional cerebral blood flow in human striate cortex, demonstrated by positron emission tomography. J. Neurophysiol. 51, 1109-1120, 1984.

11. Friedman, H. R. and Goldman Rakic, P. S. Coactivation of prefrontal cortex and inferior parietal cortex in working memory tasks revealed by $2 \mathrm{DG}$ functional mapping in the rhesus monkey. $J$. Neurosci. 14, 2775-2788, 1994.

12. Friston, K. J., Frith, C. D., Liddle, P. F., Dolan, R. J., Lammertsma, A. A. and Frackowiak, R. S. The 
relationship between global and local changes in PET scans. J. Cereb. Blood Flow Metab. 10, 458-466, 1990.

13. Friston, K. J., Frith, C. D., Liddle, P. F. and Frackowiak, R. S. Plastic transformation of PET images. J. Comput. Assist. Tomogr. 15, 634639 , 1991.

14. Friston, K. J., Frith, C. D., Liddle, P. F. and Frackowiak, R. S. Comparing functional (PET) images: The assessment of significant change. $J$. Cereb. Blood Flow Metab. 11, 690-699, 1991.

15. Frith, C. D., Friston, K., Liddle, P. F. and Frackowiak, R. S. Willed action and the prefrontal cortex in man: A study with PET. Proc, R. Soc. Lond. B. Biol. Sci. 244, 241-246, 1991.

16. Fuster, J. M., Bauer, R. H. and Jervey, J. P. Functional interactions between inferotemporal and prefrontal cortex in a cognitive task. Brain Res. 330 , 299-307, 1985.

17. Goldman-Rakic, P. S. Circuitry of primate prefrontal cortex and regulation of behaviour by representational memory. In Handbook of Physiology, Section 1; The Nervous System. Vol. V: Higher Functions of the Brain, Part 1, V. B. Mountcastle, F. Plum and S. R. Geiger (Editors), pp. 373-417. American Physiological Society, Bethesda, Maryland, 1987.

18. Grasby, P. M., Frith, C. D., Friston, K. J., Bench, C., Frackowiak, R. S. and Dolan, R. J. Functional mapping of brain areas implicated in auditory-verbal memory function. Brain 116, 1-20, 1993.

19. Haxby, J. V., Grady, C., Horwitz, B., Ungerleider, L. G., Mishkin, M., Carson, R. E., Herscovitch, P., Schapiro, M. B. and Rapoport, S. I. Dissociation of object and spatial visual processing pathways in human extrastriate cortex. Proc. Natl. Acad. Sci. USA 88, 1621-1625, 1991.

20. Jenkins, I. H., Brooks, D. J., Nixon, P. D., Frackowiak, R. S. J. and Passingham, R. E. Motor sequence learning: A study with positron emission tomography. $J$. Neurosci. 14, 3774-3790, 1994.

21. Jonides, J., Smith, E. E., Koeppe, R. A., Awh, E., Minoshima, S. and Mintun, M. A. Spatial working memory in humans as revealed by PET [see comments]. Nature 363, 623-625, 1993.

22. Kosslyn, S. M., Alpert, N. M., Thompson, W. L., Maljkovic, V., Weise, S. B., Chabris, C. F., Hamilton, S. E., Rauch, S. L. and Buonanno, F. S. Visual mental imagery activates topographically organised visual cortex: PET investigations. J. Cognit. Netrosci. 5, 263-287, 1993.

23. Liddle, P. F., Friston, K. H., Frith, C. D., Hirsch, S. R., Jones, T. and Frackowiak, R. S. Patterns of cerebral blood flow in schizophrenia. Br. J. Psychiatry 160, 179-186, 1992.

24. Lueck, C. J., Zeki, S., Friston, K. J., Deiber, M. P., Cope, P., Cunningham, V. J., Lammertsma, A. A., Kennard, C. and Frackowiak, R. S. The colour centre in the cerebral cortex of man. Nature 340, 386$389,1989$.

25. Luria, A. R. The frontal lobes and the regulation of behaviour. In The Frontal Granular Cortex and Behaviour, J. M. Warren and K. Akert (Editors), pp. 313-334. McGraw-Hill, New York, 1964.
26. Morris, R. G., Ahmed, S., Syed, G. M. and Toone, B. K. Neural correlates of planning ability: Frontal lobe activation during the Tower of London test. Neurophsychologia 31, 1367-1378, 1993.

27. Norman, D. A. and Shallice, T. Attention to action: Willed and automatic control of behaviour. Center for Human Information Processing Technical Report no. 99, (Abstr.), 1980.

28. Owen, A. M., Downes, J. J., Sahakian, B. J., Polkey, C. E. and Robbins, T. W. Planning and spatial working memory following frontal lobe lesions in man. Neuropsychologia 28, 1021-1034, 1990.

29. Owen, A. M., Doyon, J., Petrides, M., Evans, A. C. and $G j i e d d e, A$. The neural mediation of high level planning examined using positron emission tomography (PET). Soc. Neurosci. Abs. 20, 152.7 (Abstr.), 1994.

30. Owen, A. M., James, M., Leigh, P. N., Summers, B. A., Marsden, C. D., Quinn, N. P. and Lange, K. W. Fronto-striatal cognitive deficits at different stages of Parkinson's disease. Brain 115, 1727-1751, 1992.

31. Owen, A. M., Sahakian, B. K., Hodges, J. R., Polkey, C. E., Summers, B. A. and Robbins, T. W. Dopamine-dependent fronto-striatal planning deficits in early Parkinson's disease. Neuropsychology (in press).

32. Pardo, J. V., Pardo, P. J., Janer, K. W. and Raichle, M. E. The anterior cingulate cortex mediates processing selection in the Stroop attentional conflict paradigm. Proc. Natl. Acad. Sci. USA 87, 256-259, 1990.

33. Paus, T., Petrides, M,. Evans, A. C. and Meyer, E. Role of the human anterior cingulate cortex in the control of oculomotor, manual, and speech responses: A positron emission tomography study. J. Neurophysiol. 70, 453-469, 1993.

34. Petrides, M., Alivisatos, B., Evans, A. C. and Meyer, E. Dissociation of human mid-dorsolateral from posterior dorsolateral frontal cortex in memory processing. Proc. Natl. Acad. Sci. USA 90, 873-877, 1993.

35. Poline, J.-B. and Moxoyer, B. M. Enhanced detection in brain activation maps using a multifiltering approach. J. Cereb. Blood Flow Metab. 14, 639-642, 1994.

36. Raichle, M. A., Fietz, J. A., Videen, T. O., MacLeod, A.-M. K., Pardo, J. V. and Fox, P. T. Practice-related changes in human brain functional anatomy during nonmotor learning. Cereb. Cortex 4, 8-26, 1994.

37. Robb, R. A. A software system for interactive and quantitive analysis of biomedial images. In $3 \mathrm{D} \mathrm{Imag-}$ ing in Medicine, K. H. Hohne, H. Fuchs and S. M. Pizer (Editors), NATO ASI Series, Bol. F 60, 1990.

38. Robbins, T. W., James, M., Owen, A. N., Lange, K. W., Lees, A. J., Leigh, P. N., Marsden, C. D., Quinn, N. P. and Summers, B. A. Cognitive deficits in progressive supranuclear palsy, Parkinson's disease, and multiple system atrophy in tests sensitive to frontal lobe dysfunction. J. Neurol. Neurosurg. Psychiatry 57, 79-88, 1994.

39. Roland, P. E., Eriksson, L., Stone Elander, S. and Widen, L. Does mental activity change the oxidative metabolism of the brain? J. Neurosci. 7, 2373-2389, 1987. 
40. Roland, P. E. and Friberg, L. Localization of cortical areas activated by thinking. J. Neurophysiol. 53, 1219-1243, 1985.

41. Roland, P. E. and Gulyas, B. Visual imagery and visual representation. Trends Neurosci. 17, 281-287, 1994.

42. Shallice, T. Specific impairments of planning. Phil. Trans. R. Soc. Lond. Biol. 298, 199-209, 1982

43. Shallice, T., Fletcher, P., Frith, C. D., Grasby, P., Frackowiak, R. S. and Dolan, R. J. Brain regions associated with acquisition and retrieval of verbal episodic memory. Nature 368, 633-635, 1994.

44. Silbersweig, D. A., Stern, E., Frith, C. D., Cahill, C., Schnorr, L., Grootoonk, S., Spinks, T., Clark, J., Frackowiak, R. and Jones, T. Detection of thirtysecond cognitive activations in single subjects with positron emission tomography: A new low-dose $\mathrm{H}_{2}(15) \mathrm{O}$ regional cerebral blood flow three-dimensional imaging technique. J. Cereb. Blood Flow Metab. 13, 617-629, 1993.

45. Spinks, T. J., Jones, T., Bailey, D. L., Townsend, D. W., Grootoonk, S., Bloomfield, P. M., Gilardi, M. C., Casey, M. E., Sipe, B. and Reed, J. Physical performance of a positron tomograph for brain imaging with retractable septa. Phys. Med. Biol. 37, $1637-1655,1992$.
46. Stephan, K. M., Fink, G. R., Passingham, R. E., Silbersweig, D., Ceballos-Bauman, A. O., Frith, C. D. and Frackowiak, R. S. J. Imagining the execution of movements. J. Neurophysiol. (in press).

47. Stuss, D. T. and Benson, D. F. The Frontal Lobes. Raven Press, New York, 1986.

48. Talairach, J. and Tournoux, P. Co-Planar Stereotaxic Atlas of the Human Brain. Thieme Medical Publishers Inc., New York, 1988.

49. Tulving, E., Kapur, S., Markowitsch, H. J., Craik, F. I., Habib, R. and Houle, S. Neuroanatomical correlates of retrieval in episodic memory: auditory sentence recognition. Proc. Natl. Acad. Sci. USA 91, 2012-2015, 1994.

50. Walsh, K. W. Neuropsychology: A Clinical Approach. Churchill Livingstone, Edinburgh, 1978.

51. Watson, J. D., Myers, R., Frackowiak, R. S., Hajnal, J. V., Woods, R. P., Mazziotta, J. C., Shipp, S. and Zeki, S. Area V 5 of the human brain: evidence from a combined study using positron emission tomography and magnetic resonance imaging. Cereb. Cortex 3, 79-94, 1993.

52. Woods, R. P., Cherry, S. R. and Mazziotta, J. C. Rapid automated algorithm for aligning and reslicing PET images. J. Comput. Assist. Tomogr. 16, 620-633, 1992.
Three scans for easy problems

$\begin{array}{lllll}1 & 4 & 5 & 2 & 5 \\ 4 & 5 & 1 & 4 & 6 \\ 5 & 5 & 1 & 4 & 4\end{array}$

Three scans for difficult problems

\begin{tabular}{|c|c|c|c|c|c|c|c|c|c|c|}
\hline & & & & & & \multicolumn{5}{|c|}{ [scan these .....] } \\
\hline 2 & 1 & 5 & 3 & 3 & 6 & 3 & 4 & 5 & 4 & 2 \\
\hline 4 & 2 & 2 & 6 & 3 & 1 & 3 & 3 & \multicolumn{3}{|c|}{ [scan these .....] } \\
\hline & 3 & 6 & 2 & 3 & 3 & 2 & \multicolumn{4}{|c|}{ [scan these $\ldots . . . \ldots \ldots \ldots \ldots . . . . . .}$. \\
\hline
\end{tabular}

Appendix 1. Problem sequences

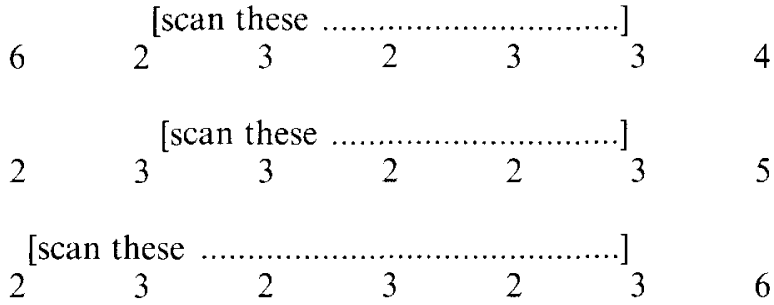

(1)

